\title{
APPLICATION OF PREFABRICATED PANELS FOR THE ENERGY RETROFIT OF PORTUGUESE RESIDENTIAL BUILDINGS FACADES: A CASE STUDY
}

\author{
J. SOUSA ${ }^{1}$
}

\begin{abstract}
This article aims to evaluate the potential application of prefabricated panels in energy retrofit of facades in the Portuguese building stock. The fundamentals of this study were part of Annex 50, which was an international ECBCS IEA project, with the purpose of developing an innovative concept of building renovation for the most representative buildings based on prefabricated systems. To analyze the potential application of energy retrofit using prefabricated panels, was important to know the reality of the existing building stock and its morphology. To know the reality of the building stock, an analysis was done based on the existing statistical data and to find the most representative residential buildings, target of the study, three criteria were defined: buildings built before 1990, with 2 to 6 floors and with renovation needs in the exterior envelope.

In the absence of statistical information about buildings morphology, a research work was done in the field. During the collection of data a methodology was developed in which each opening was classified according to a code with three parameters. In the end of the classification, 29 final codes were achieved and was verified that three types of panels have a higher probability of being applied.
\end{abstract}

Keywords: Prefabrication Panels Systems; Facades Retrofit; Low Energy Renovation; Sustainability.

\section{INTRODUCTION}

Forty decades ago the world felt the effects of the first oil crisis with a generalized widespread price hike of energy goods [1]. Since this time there is a growing concerning about energy efficiency questions, climatic changes and environmental problem issues due to a widespread fossil fuel dependence and excessive energy consumption [2]. This dependence on fossil fuels by some importer countries is considered as a threat to their sovereignty by Kyoto protocol [3-5]. Portugal is one of these threatened countries with an energy resource importation about $83 \%$ of the country total needs [6-8]. This scenario originated a bounce back in the country energy politics goals which pretend a reduction of energy dependence through the increase of renewable energy sources [9].

1 Master in Civil Engineering, Faculty of Engineering, University of Porto, Portugal. E-mail:j.raquel. sousa@gmail.com Address: Rua do Neiva, 274200 Porto 
In 1973 (when the first oil crisis was held), the housing sector was pointed as a strategic piece to reduce the European energy consumption in households [10]. Nowadays the building sector represents about $40 \%$ of the total energy consumptions in Europe, being one of the major responsible for $\mathrm{CO}_{2}$ emissions, and there are expectations of a continuing growth tendency trend in energy consumptions in this sector until 2050 [11-13]. This tendency in energy consumes in the housing sector can be associated to the high thermal comfort patterns of a significant part of the population which demand for heating and cooling devices in order to guarantee a constant temperature during the year [14]. The acquisition of acclimatization devices is now considered necessary to achieve a basic comfort level in buildings and their sales have been increasing over the years [15].

As a major consumer of energy, the building sector presents a significant importance in the achievement of energy efficiency measures. With the adoption of efficiency measures the energy consumption can be reduced in more than $50 \%$, representing about 400 million tones of reduced $\mathrm{CO}_{2}$ for each year [16]. If the retrofit measures mentioned in the EPBD recast were implemented in the European building stock, including multi-family houses, non-residential buildings and all single-family houses, the amount of $\mathrm{CO}_{2}$ emission savings could reach to $398 \mathrm{Mt} / \mathrm{a}[17,18]$. Some of these retrofit measures are related with the retrofitting of building envelope, i.e. insulation improvements of external walls, window frames, floors and roof structures as well as measures to reduce the heat losses through ventilation.

The aim of the international project IEA ECBCS Annex 50 - Prefabricated Systems for Low Energy Renovation of Residential Buildings, was to develop a new concept of integrated low energy retrofit for a whole building using prefabricated solutions [19]. The development of the retrofit prefabricated modules for facades was performed in order to develop advanced energy retrofit strategies. These modules also have the function of insulating the building envelope with integrated systems for heating, cooling and ventilation [20].

Energy retrofit measures in buildings are often tackled when they are unavoidable and usually lead to different and partial uncoordinated interventions on time that might result in higher costs for the properties owners. With the development of these retrofit prefabricated modules is possible to establish a long-term advanced retrofit building strategy that establishes a holistic building retrofit approach for the remaining life cycle of the building [21].

In order to evaluate the potential of low energy renovation using prefabricated panels it was necessary to consider two subjects, namely, the existing housing stock and the available prefabrication solutions. The present study was carried out considering the three types of retrofit prefabricated modules developed in the IEA ECBCS Annex 50 project by different represented countries (Fig. 1).

It was carried out a detailed study of the Portuguese housing stock according with the last known statistical data (Table 1). In 2011 there were 3.544 .389 buildings in Portugal mainland and islands nevertheless, not all the existing buildings were able to 
be renovated using this innovative solution. The present study was mainly focused on residential buildings so all the non mainly residential buildings, the collective buildings i.e. hotels, convents and barracks, and the non classic residences i.e. tents and stalls were disregarded. Moreover a number of variables were established in order to define those buildings which potentially present the most favourable conditions for energy retrofit using prefabricated facade panels.

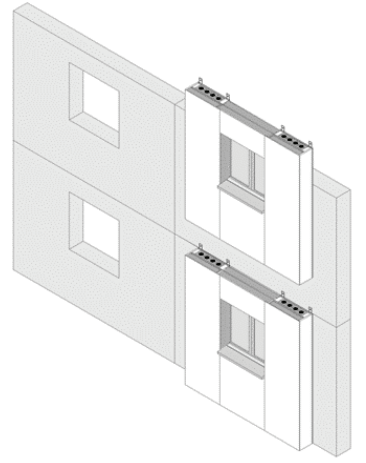

Swiss module

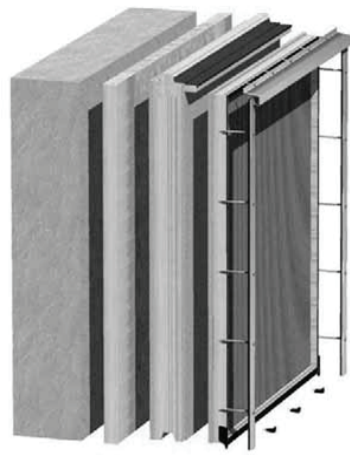

Austrian module

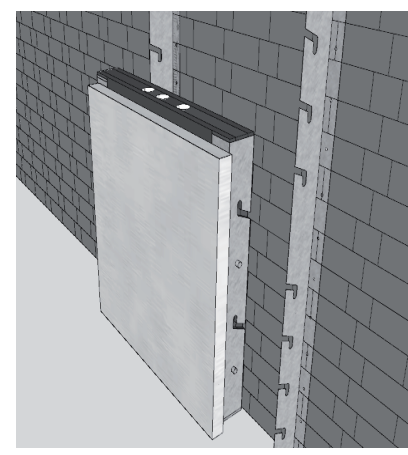

Portuguese module

Fig. 1. Examples of prefab modules developed by IEA ECBCS Annex 50 project [22]

Table 1

Statistical characterization of the buildings with renovation needs in the exterior walls and window frames per period of construction.

\begin{tabular}{|c|c|c|}
\hline Building period & $\begin{array}{c}\text { Number of buildings with } \\
\text { reparations needs in the exterior } \\
\text { walls and window frames }\end{array}$ & $\begin{array}{c}\text { Number of Buildings with } \\
\mathbf{2} \text { to } 6 \text { floors }\end{array}$ \\
\hline Before 1919 & 139.612 & 206.343 \\
\hline $1919-1945$ & 198.592 & 305.696 \\
\hline $1946-1960$ & 220.266 & 387.340 \\
\hline $1961-1970$ & 194.420 & 408.831 \\
\hline $1971-1980$ & 209.771 & 588.858 \\
\hline $1981-1990$ & 154.237 & 578.845 \\
\hline & $\sum=1.116 .898$ & $\sum=2.475 .913$ \\
\hline
\end{tabular}

Estimating the potential residential buildings with better conditions for retrofit using prefabricated facade panels is only one part of the target. This advanced retrofit building strategy through the implementation of prefabricated panels requires other issues to be 
addressed. i.e. architecture of the facades. For the production of prefabricated panels to be economically justifiable it is necessary to produce them in a large scale. In order to know the shapes of the panels, it was previously necessary to know the morphology of the buildings and the most representative types of openings in the facades. In the absence of statistical information about this subject, a research work was done in the field in two stages. During the collection of data in the field a methodology was developed in which each opening was classified according to a code with three parameters: the type of opening, the vertical configuration of the opening and the horizontal configuration of the opening.

From the observation process 132 buildings openings were classified and 29 final codes were achieved. As mentioned the observation was done in two stages to evaluate identify possible variances and the buildings were chosen randomly in a geographical area as broad as possible, but with significant urban characteristics.

The impact of politics measures adopted in the energy efficiency of dwellings is still very poorly felt in European economy. However with the increasing in primary energy goods prices, the household's energy bills will rise and potentiate the energy retrofit market [23]. Through providing information to owners on their energy consumptions it was demonstrated that energy bills can be substantially reduced [24]. Besides the initial investments required for this type of innovative energy efficient systems solutions are usually higher the amortization of equipment can be done during the remaining life cycle of the building translating into a cost-benefit optimum situation.

\section{THE PORTUGUESE BUILDING STOCK ANALYSIS}

According with the statistical count done, in 2011, were counted 3.544 .389 buildings and 5.859.540 lodging. A building can be defined as an independent construction that comprehends one or more lodgings, divisions or other spaces, independently, if the utilization goal is commercial, industrial, cultural, residential or any other. Lodging is a distinct and independent place that, by the way it was constructed, reconstructed, amplified or transformed is intended to be used as human habitation.

The majority of Portuguese housing (about 99,7\%) correspond to classic family lodging. A classic family lodging can be define as lodging with a room or a set of rooms and other attachments that by the way that were built, rebuilt or converted are intended to be a permanent home of a family.

The majority of Portuguese building stock was built fifty, forty years ago mainly during the 1960's, 1970's and 1980's decades, representing about $51 \%$ of all the Portuguese Building Stock (Fig. 2) [25].

Nowadays a considerable part of this building stock can be considered obsolete because a great part presents some repair needs [26]. Back then the thermal regulation was inexistent, reason why the buildings built during 1960's, 1970's and 1980's tend to consume more energy however they also present major potential for energy saving 
[27]. In 2010, the residential sector was the third largest energy consumer presenting energy consumptions about $18 \%$ of the total consumptions and forecasts indicate an upward trend in energy consumption in the housing sector particularly of electrical energy [28].

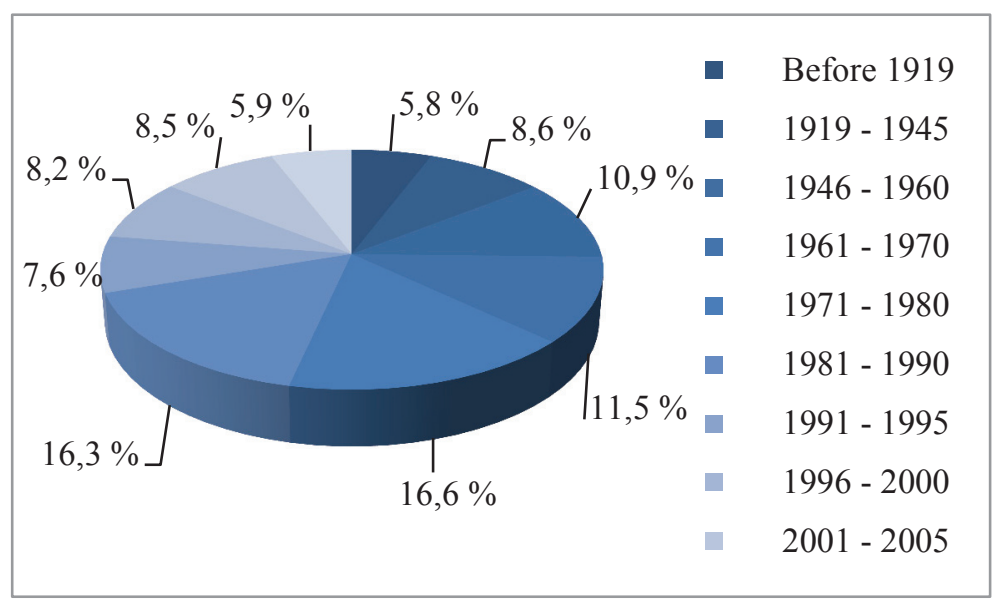

Fig. 2. Percentage of buildings according with period of construction

Since the last forty decades Portugal experienced an expansion of the building stock. Nevertheless the consequence of this new construction tendency was an absence of investment in rehabilitation and conservation of the existing building stock. Statistics from Census 2011 revealed that about $29 \%$ of the Portuguese housing needs some kind of reparation (Fig. 3).

The precedent strong investment in construction, the freezing of rents prior to 1990 and, lately, the reduction in the concession of loans to investors by the banks due to the economical crisis are the most significant features that lead to the current poor state of repair of the Portuguese building stock [29].

Exterior walls and window frames presents the majority of repair works that are needed on buildings. However, also in coverage and in the buildings structure are needed some repair works (Fig. 4).

The rehabilitation should bring back to the market, unoccupied or energetically inefficient buildings, increasing also its real estate value. In response to social needs, the investment on rehabilitation would contribute to increase the life quality of the residents and to create new job opportunities. The reduction of the energy consumptions, that might be achieved, would be economically advantageous, both for the residents and the country and would ensure the intergenerational sustainability of the building stock. 


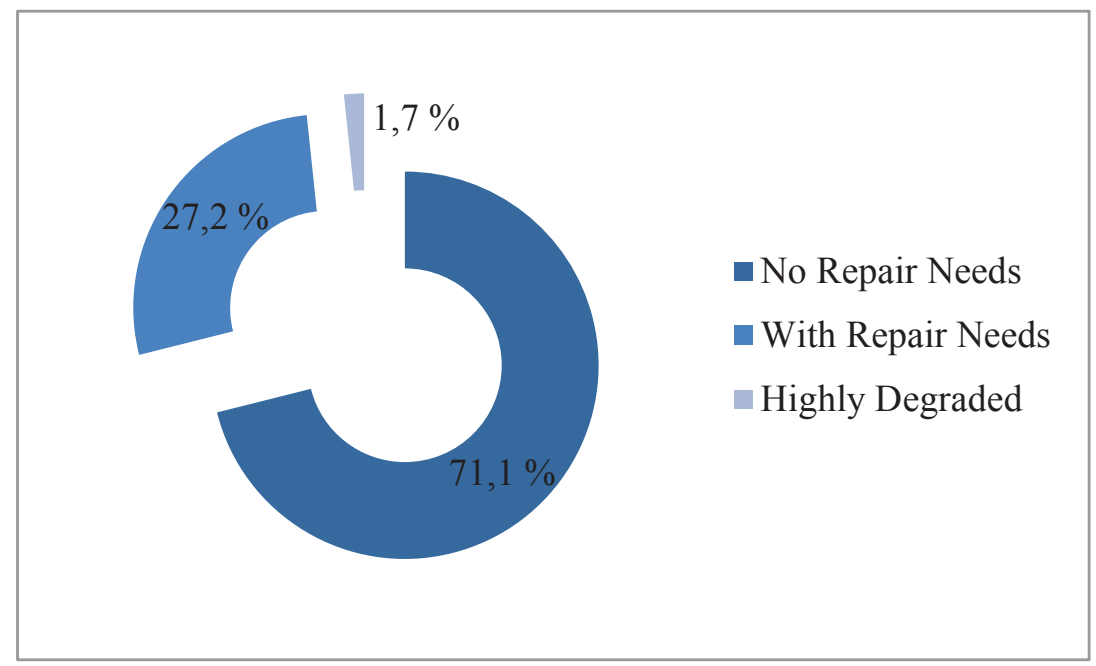

Fig. 3. Percentage reparation needs in buildings

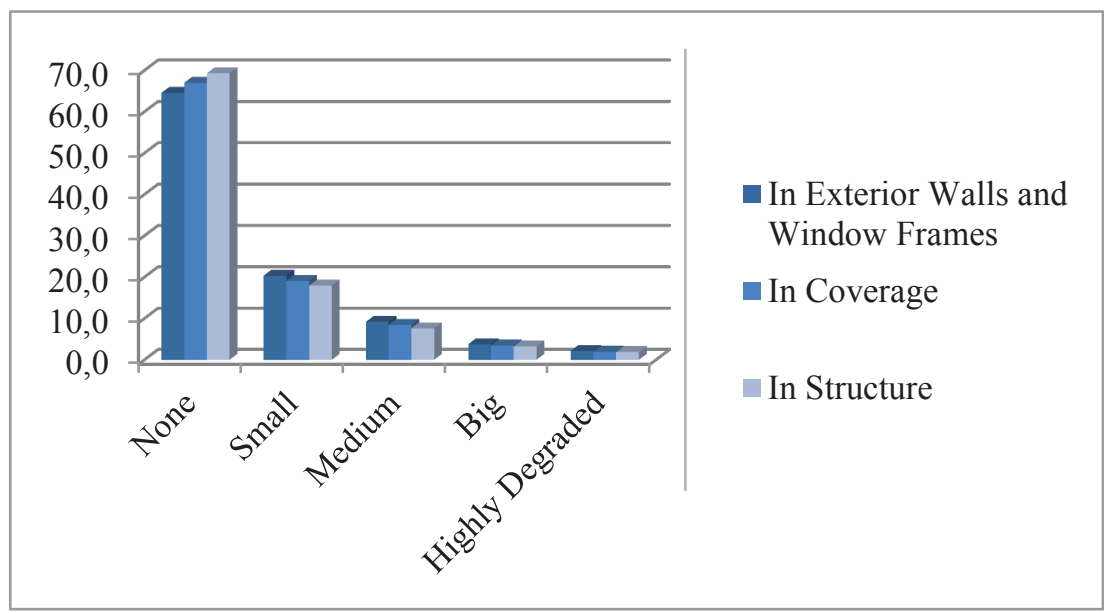

Fig. 4. Number of buildings by reparation needs for part of the building

Although the positive effects for the society, the rehabilitation in general and the energy rehabilitation of buildings in particular does not play a significant role in the Portuguese construction market. The absence of a wide spread awareness about the subject is perhaps one of the most important difficulties to its promotion. 


\section{Methodology}

\subsection{IDENTIFICATION OF THE STATISTICAL SAMPLE}

In order to evaluate if there were the necessary conditions for the application of this technique it was necessary to previously know the existing building stock. The specificities of the rehabilitation market and of the prefabrication industry required an analysis of the stock in order to realize if there were a representative number of buildings with certain characteristics. Nevertheless the target of study was focused on classic family residential buildings, reason why every non classic, collective and mainly non-residential building was disregarded of the analysis as mentioned previously.

The totality of the buildings existing in the Portuguese building stock consists of the total sample. From this sample were subtracted the three above mentioned cases, in the end the pretended statistical sample was obtained (Fig. 5).

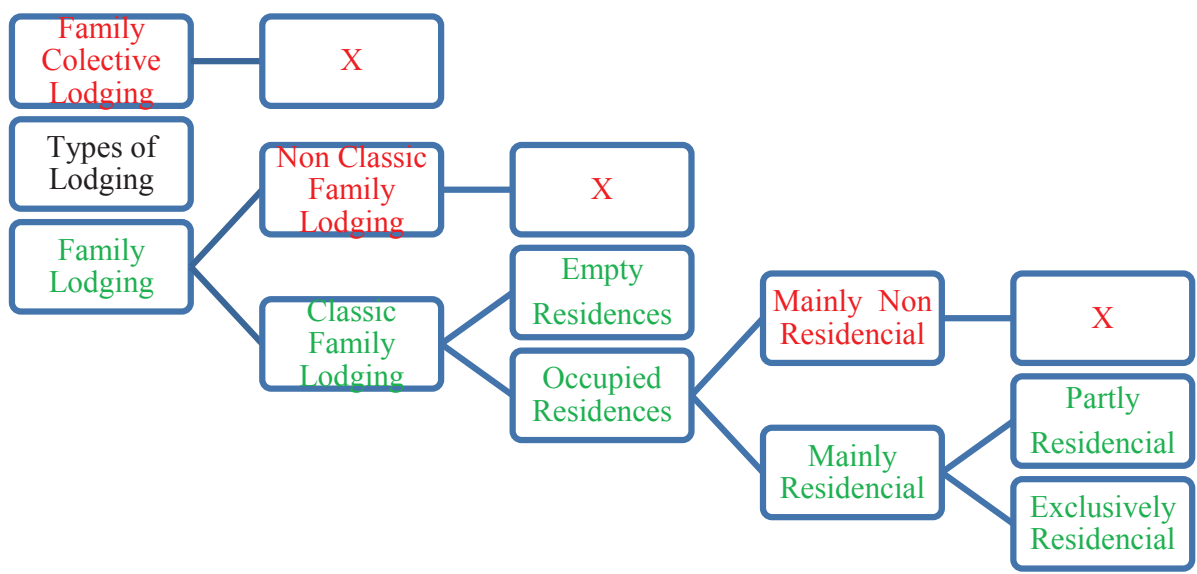

Fig. 5. Total sample of the building stock considering the target (in green) and non target buildings (in red)

A sample of 3.507.059 building was obtained and available to be part of the study. Notwithstanding not all these buildings might be targets of a renovation using such an innovative technique. In order to find the existing buildings in building stock with more appetence to be a target of such type of renovation a selection of three criteria were defined. These criteria were related with number of floors, the period of construction and the renovation needs in the exterior walls and window frames and the specific reasons for their choice are explained in the next subchapter. Nevertheless these criteria were defined having in account that for a full potential application of prefabricated panels it is necessary to produce then in a large and economical scale. 


\subsection{Selection of the CRiteria}

\subsubsection{Number of floors}

The first variable considered in the selection was the number of floors of the buildings. In this variable all the buildings with less than two or more than seven floors were excluded from the statistical representation.

Actual prefabrication processes assume that the final product is independent of its final utilization and application. For a major impact in the market of the prefabricated products, in this case a prefabricated panel for facades, it is expected that its application could be possible in any facade independently of the number of floors. However the absence of architectural patterns in the Portuguese buildings facades, particularly in those buildings with less than one floor, is a serious obstacle to the production of massive scale prefabricated panels.

This exclusion represents about $40 \%$ of the building stock which is a significant percentage (Fig. 6). However due the variability of facades it is difficult to develop prefabricated panels buildings facades in a massive scale.

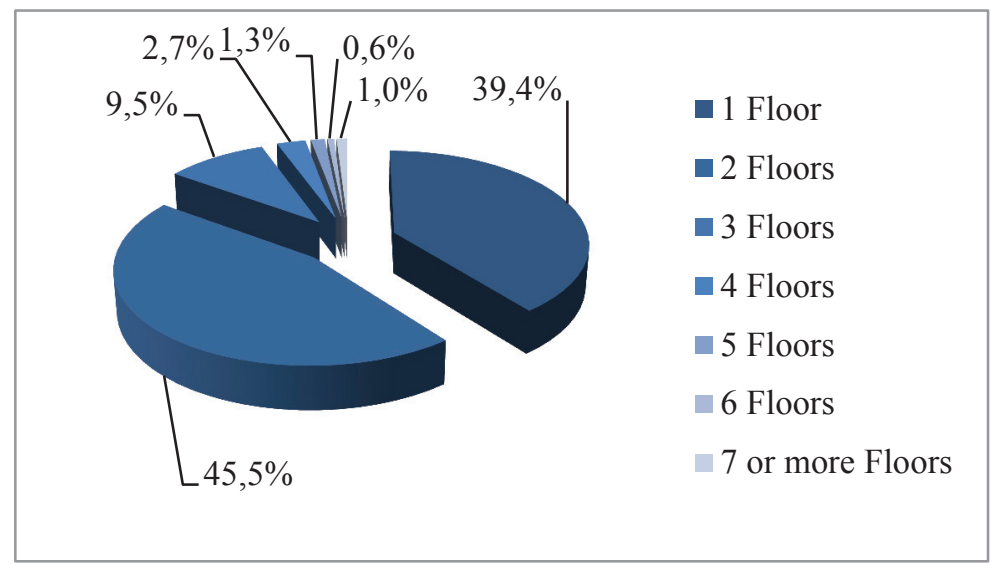

Fig. 6. Percentage of buildings per number of floors

The buildings with more than seven floors were also excluded from the selection. In this case was considered that the high altitude of the buildings can be an obstacle to assembly of the prefabricated systems. The installation of the prefabricated pieces should be as faster as possible using light and simple devices in order to diminish the final price of the pieces. The buildings with more than seven floors represent only $1 \%$ of the building stock. 
The remaining buildings were considered to be able of the study and together represent about $60 \%$ of the stock.

\subsubsection{Conservation of Exterior Walls and Window Frames}

There are 1.062.939 buildings with any kind of reparation needs (from small reparations to highly degraded buildings) representing about $35,5 \%$ of the total building stock. However this is a general number which don't specify the local of the building where the intervention is needed. In order to restrict the statistic sample, only the conservation state of exterior walls and window frames was considered. The prefabricated panels are going to be applied in the buildings facades with a double purpose, the reduction of energy consumptions in the households but also the possible retrofit of facades in a poor state of conservation. Approaching specifically the conservation of the building exterior shell there are 1.256.094 buildings needing some kind of intervention in the façade or in the window frames.

\subsubsection{Year of Construction}

According with the last Census there are ten defined periods of construction. In the variable year of construction all the buildings after 1990 were excluded. With this criterion the main gold was to assure that the most recently buildings were not considered.

Moreover those buildings built after 1990 were built according with the first thermal regulation standards and in general are the ones with less conservation and maintenance needs in the facades as it is possible to see in the Fig. 7.

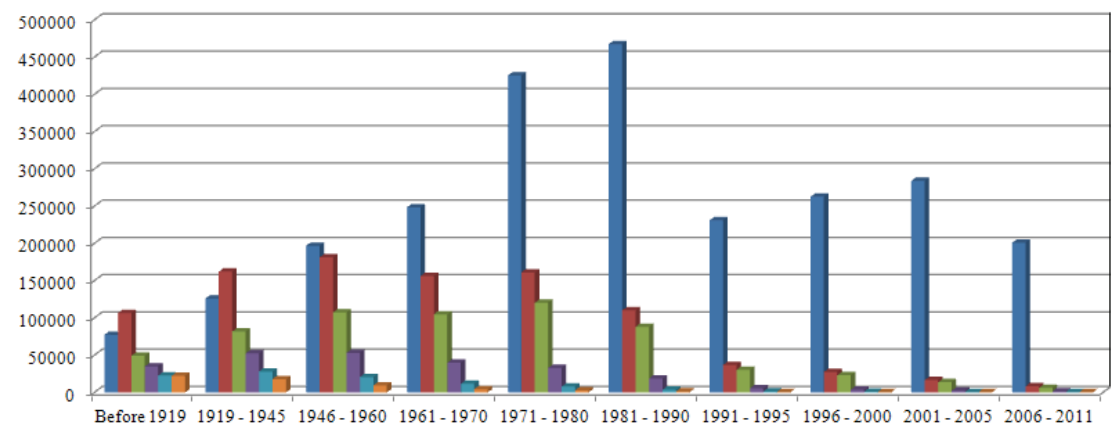

- Without Repair Needs

- With Repair Needs

w Small Repair Needs

Medium Repair Needs

- Large Repair Needs

m Highly Degraded

Fig. 7. Number of buildings with repair needs per period of construction

\subsubsection{Statistic Identification of the Target Residential Buildings}

In order to find the eligible buildings to apply the prefabricated panel's technique the results of the variables previously defined were combined. The buildings which satisfy 
the criteria of the variables are the ones with best potential to apply this technique in the energy retrofit of facades as is illustrated in Fig. 8.

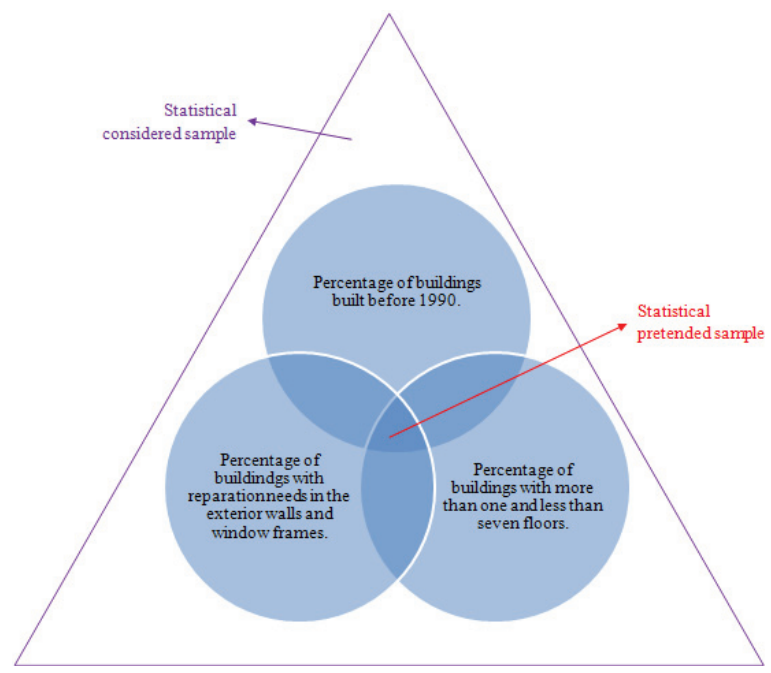

Fig. 8. Scheme with the statistical sample and the three defined variables

Considering the general sample identified in the totality of the Portuguese building stock (3.507.059 buildings) $31,85 \%$ of this buildings have needs of reparation and conservation of its exterior walls and window frames.

Considering the buildings with more than one floor and less than seven floors built before 1990 is possible to conclude that exist about 2.475 .913 buildings which correspond to $70,8 \%$ of the statistical considered sample (3.507.059 buildings). In order to find the statistical pretended sample three major groups were identify (Fig. 9), namely:

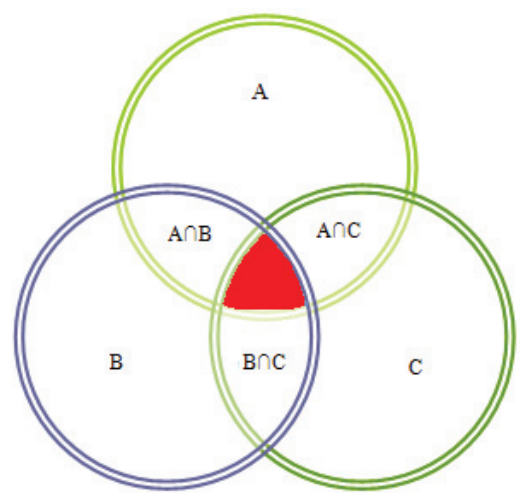

Fig. 9. Scheme with all the adopted variables. 
- Buildings built before 1919 to 1990 - Group A;

- Buildings needing reparation in exterior walls and window frames - Group B;

- Buildings with 2 to 6 floors - Group C.

Trough statistical information it is possible to know $\mathrm{A} \cap \mathrm{B}$ and $\mathrm{A} \cap \mathrm{C}$ but the pretention of this part of the study is to know $(A \cap B) \cap C$, which is the part marked in red represented on Fig. 9. Nevertheless to know $(A \cap B) \cap C$ it is also necessary to know $\mathrm{B} \cap \mathrm{C}$ results, but is no statistical information on this range reason why the following estimation was done.

$$
\frac{A \cap B}{\text { Sample }}=\frac{1.116 .898}{3.507 .059}=0,318=31,8 \%
$$

Assuming this percentage is applied to $\mathrm{A} \cap \mathrm{C}$ :

$$
0,312 \times 2.475 .913=772.485 \text { Buildings }
$$

Through this estimative it is possible to conclude that 772.485 buildings with 2 to 6 floors build before 1919 and 1990 have reparation needs in the façade and window frames. This value represents approximately $22 \%$ of the total statistical considered sample.

\subsection{Potential of application of the PREFABricated SOlUtions}

\subsubsection{Collecting the data on field}

To evaluate the potential application of prefabricated panels in those buildings which respect the variables defined previously, a research work was done in the field divided in two stages. During the collection of data a methodology was developed in which each opening was classified according to a code with three parameters: the type of opening, the vertical configuration of the opening and the horizontal configuration of the opening.

Both the collecting stages were in Oporto district area. In the first stage were collected in some councils a bigger sample, namely, in Oporto, Póvoa de Varzim and Vila do Conde. In the second stage, the sample observed was smaller, were also observed buildings from the Oporto district but from different councils.

In totality were observed 1790 openings in 132 buildings. In the first sample were counted 1282 openings in 93 buildings. From this sample the majority of buildings were placed in Oporto with 69 buildings, 14 buildings were counted in Póvoa de Varzim and 10 buildings in Vila do Conde. In the second stage were observed 509 openings in 39 buildings, 7 in Espinho, 6 in Vila Nova de Gaia, 7 in Valongo, 10 in Maia, 6 in Matosinhos and 3 buildings in Santa Maria da Feira. This cont was done in two stages with the purpose of finding if there was any match between the two sample codes. 


\subsubsection{The Parameters to Analyse}

\subsubsection{Type of Opening}

Each opening was classified according with three parameters. The first parameter is entitled by type of opening and is possible to distinguish among three possible codes. To each opening is only possible to attribute one code (Table 2).

Table 2

Characterization of facades morphology - Types of openings

\begin{tabular}{|c|c|c|}
\hline $\begin{array}{c}\text { Cod. 1 } \\
\text { Window }\end{array}$ & $\begin{array}{c}\text { Cod. 2 } \\
\text { Window behind a balcony }\end{array}$ & $\begin{array}{c}\text { Cod. 3 } \\
\text { Door behind a balcony }\end{array}$ \\
\hline & & \\
\hline
\end{tabular}

\subsubsection{Vertical Configuration of the Openings}

The second parameter associated to the analysis of application of prefabricated panels in facades, to be considered is the vertical configuration of the openings. In this parameter is pretended to evaluate if there is or not any alignment between the openings. If there is a vertical alignment of the several openings of the building facade this should be classified the code number 1. Otherwise if there isn't a vertical alignment of the building facade openings it should be attributed the code number 2 (Table 3). 
Table 3

Characterization of facades morphology - Vertical position of openings.

\begin{tabular}{|c|c|}
\hline Cod. 1 & Cod. 2 \\
Aligned Openings & Not Aligned Openings \\
\hline I & I I I I I I I I I I I \\
\hline
\end{tabular}

\subsubsection{Horizontal Configuration of the Openings}

The third parameter evaluates the horizontal configuration of the openings. In this parameter there considered eleven possible horizontal positions of the openings, or eleven possible codes to attribute to each opening. However though the visualization on site it was found that for one single opening could be applied more than one code. In these situations was decided to attribute the code corresponding to the situation that could be conditioning for the application of the prefabricated panels.

The openings distance classification was based in local visual observation and classification, in order to better understand the difference between a short distance opening and a large distance opening Fig. 10, represent examples of the mentioned situations.

Although most of the openings were instinctively classifiable, there were doubtful situations. In these situations it was considered the area of the opening i.e. openings with $1 \mathrm{~m} 2$ or $5 \mathrm{~m} 2$ of area distancing the same distance of other opening located in the façade have different codes classification.
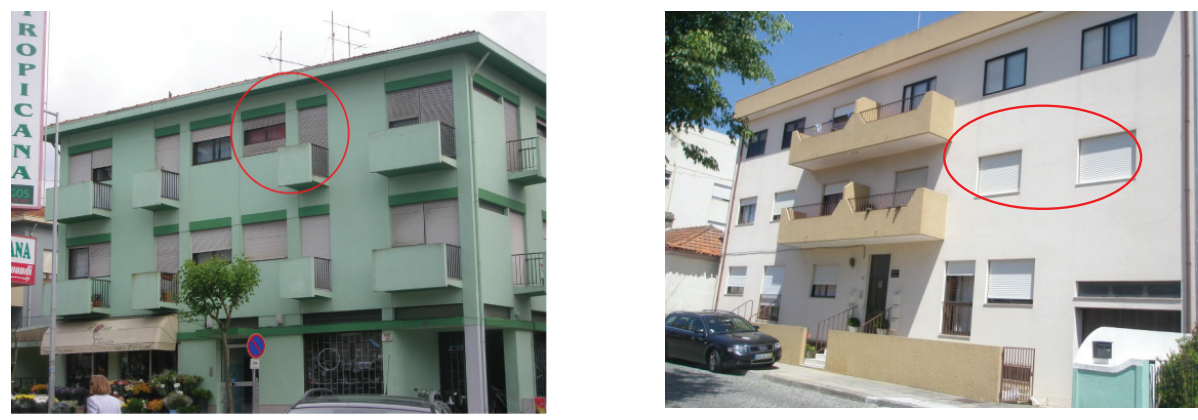

Fig. 10. Example of a building located in Espinho with a short distance between openings (left picture) and a example of a building located in Póvoa do Varzim with a large distance between openings (right picture) 
Table 4

Characterization of facades morphology - horizontal position of openings

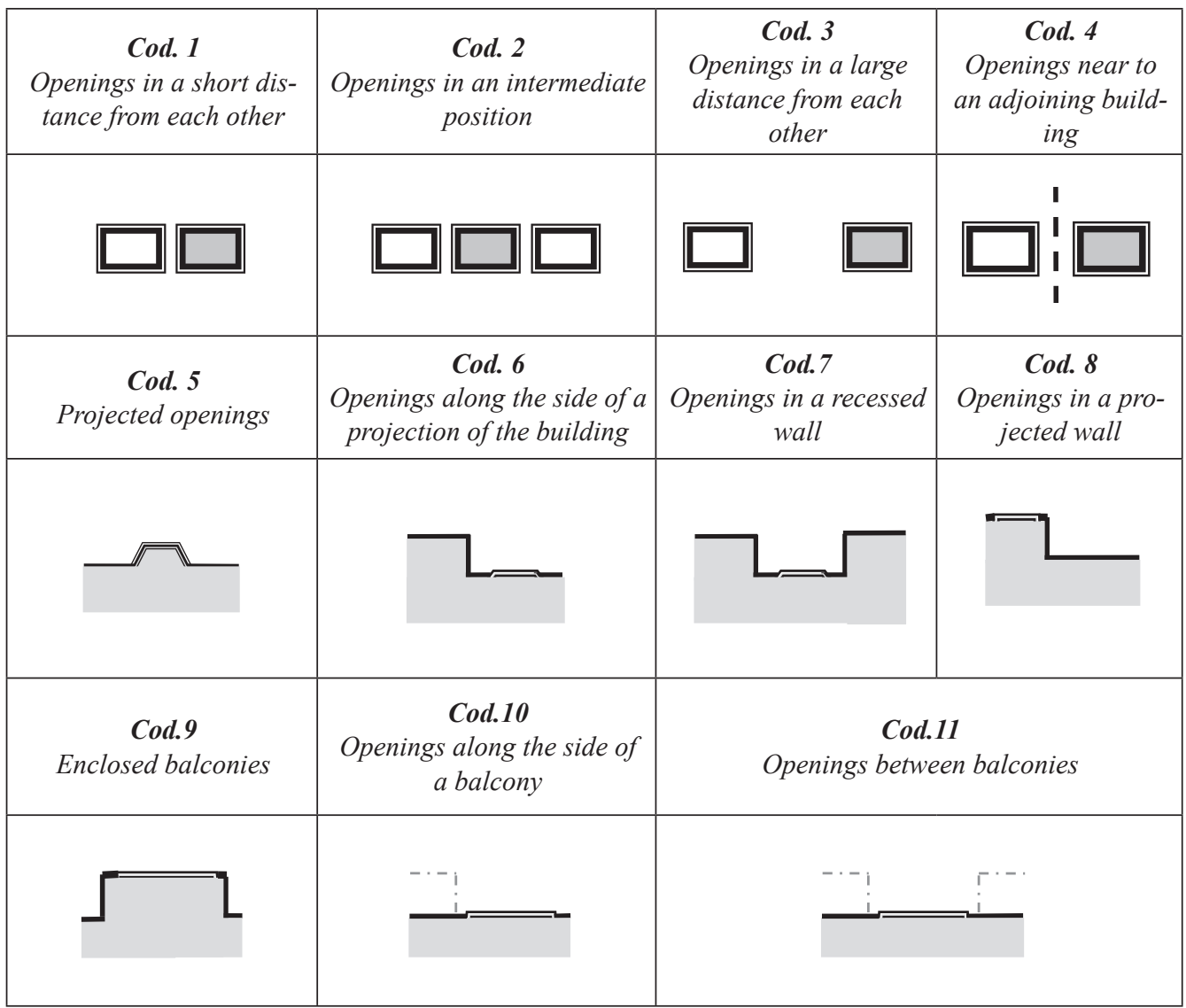

\subsubsection{The Results of the first sample}

The final code is the set of codes attributed for each parameter. It was possible to determinate 28 types of possible combinations which are exposed in Table 5. There is possible to find the number of occurrences for each code and the respective percentage. Nevertheless only the codes underlined in grew were considered statistically relevant (all the code combination with less than 3\% representation were excluded).

From the 28 first sample final codes results only 10 codes were elected representative being the combination 113 the most representative sample of the first stage collection with an total observation percentage of $26,3 \%$. 
Table 5

Statistical characterization of the final codes obtained in the first sample.

\begin{tabular}{|c|c|c|c|c|c|}
\hline Final Code & $\begin{array}{l}\text { Number of } \\
\text { Occurrences }\end{array}$ & $\begin{array}{l}\text { Percentage } \\
(\%)\end{array}$ & Final Code & $\begin{array}{l}\text { Number of } \\
\text { Occurrences }\end{array}$ & $\begin{array}{c}\text { Percentage } \\
(\%)\end{array}$ \\
\hline 111 & 129 & 10,1 & 217 & 75 & 5,9 \\
\hline 112 & 16 & 1,2 & 218 & 8 & 0,6 \\
\hline 113 & 337 & 26,3 & 311 & 73 & 5,7 \\
\hline 114 & 45 & 3,5 & 312 & 7 & 0,5 \\
\hline 115 & 3 & 0,2 & 313 & 128 & 10,0 \\
\hline 116 & 18 & 1,4 & 314 & 8 & 0,6 \\
\hline 118 & 41 & 3,2 & 316 & 12 & 0,9 \\
\hline 119 & 12 & 0,9 & 317 & 149 & 11,6 \\
\hline 121 & 17 & 1,3 & 318 & 4 & 0,3 \\
\hline 123 & 16 & 1,3 & 321 & 2 & 0,2 \\
\hline 211 & 62 & 4,8 & 323 & 2 & 0,2 \\
\hline 212 & 1 & 0,1 & 1110 & 70 & 5,5 \\
\hline 213 & 5 & 0,4 & 1111 & 36 & 2,8 \\
\hline \multirow[t]{2}{*}{214} & 4 & 0,3 & 1210 & 2 & 0,2 \\
\hline & & & Total & 1282 & $100 \%$ \\
\hline
\end{tabular}

\subsubsection{The Results of the second sample}

The evaluation of the second sample was done using the same parameters used in the first sample, types of openings, vertical position of openings and horizontal position of openings. After the classification of the openings of the buildings analyzed in the second sample the final codes achieved are represented in Table 6.

Like in the first sample every code combination without than 3\% representatively was excluded from the code combination. From the 18 code classification achieved only 8 combinations were considered. In the second sample the most common combination was the code 113 like happed before in the first sample. The final 8 combinations achieved in the second sample are also present in the first sample nevertheless in the second sample was possible to identify combinations inexistent in the first. 
Table 6

Statistical characterization of the final codes obtained in the second sample.

\begin{tabular}{|c|c|c|c|c|c|}
\hline Final Code & $\begin{array}{l}\text { Number of } \\
\text { Occurrences }\end{array}$ & $\begin{array}{c}\text { Percentage } \\
(\%)\end{array}$ & Final Code & $\begin{array}{l}\text { Number of } \\
\text { Occurrences }\end{array}$ & $\begin{array}{c}\text { Percentage } \\
(\%)\end{array}$ \\
\hline 111 & 31 & 6,1 & 211 & 46 & 9,1 \\
\hline 112 & 2 & 0,4 & 213 & 12 & 2,4 \\
\hline 113 & 165 & 32,5 & 217 & 2 & 0,4 \\
\hline 114 & 3 & 0,6 & 311 & 56 & 11,0 \\
\hline 116 & 3 & 0,6 & 313 & 86 & 16,9 \\
\hline 117 & 1 & 0,2 & 317 & 28 & 5,5 \\
\hline 118 & 18 & 3,5 & 1110 & 41 & 8,0 \\
\hline 119 & 2 & 0,4 & 1111 & 2 & 0,4 \\
\hline \multirow[t]{2}{*}{121} & 9 & 1,8 & 1112 & 1 & 0,2 \\
\hline & & & Total & 508 & $100 \%$ \\
\hline
\end{tabular}

\subsubsection{The Final Results of both sample}

The final codes of sample one and two were assembled in Table 7 where is possible to analyze the total number of openings with a certain type of characteristics corresponding to the attributed code.

After the determination of the final percentages associated to each final code it is possible to obtain the potential number of openings which could be a target of thermal retrofit employing the prefabricated models defined in the international study IEA ECBCS Annex 50. In Table 8 to 10 is possible establish an association between the final codes obtained through local observation, the possible types of panels to be applied and an estimation of the total number of openings in the selected building stock which could be subjected to this kind of intervention in the facade. The final percentages achieved in Table 8, 9 and 10 were the sum of the of the totality percentages of each code which are summarized in Table 7 . The number of potential openings was estimate applying the total percentages of the most representative codes to the 772.485 buildings which represent the statistical pretended sample determined in subchapter 3.2.4.

It was possible to establish a connection between the 132 buildings observed in loco and the statistical determined sample ( 772.485 buildings) because all the buildings observed respect the defined variables established to determine the sample, namely, buildings with more than one and less than seven floors, with reparation need in the exterior facades and window frames and built before 1990. Nevertheless it is not possible 
to affirm that $43,1 \%$ (in the case of Table 8 panels) can be apply to the hole reality of the building stock. This percentage corresponds to tax of application estimated for the sample of 772.485 buildings.

Table 7

Final Statistical Characterization of both samples.

\begin{tabular}{|c|c|c|c|c|c|}
\hline Final Code & $\begin{array}{c}\text { Number of } \\
\text { Occurrences }\end{array}$ & $\begin{array}{c}\text { Percentage } \\
(\%)\end{array}$ & Final Code & $\begin{array}{c}\text { Number of } \\
\text { Occurrences }\end{array}$ & $\begin{array}{c}\text { Percentage } \\
(\%)\end{array}$ \\
\hline 111 & 160 & 8,9 & 217 & 77 & 4,3 \\
\hline 112 & 18 & 1,0 & 218 & 8 & 0,4 \\
\hline 113 & 502 & 28,0 & 311 & 129 & 7,2 \\
\hline 114 & 48 & 2,7 & 312 & 7 & 0,4 \\
\hline 115 & 3 & 0,2 & 313 & 214 & 12,0 \\
\hline 116 & 21 & 1,2 & 314 & 8 & 0,4 \\
\hline 117 & 1 & 0,1 & 316 & 12 & 0,7 \\
\hline 118 & 59 & 3,3 & 317 & 177 & 9,9 \\
\hline 119 & 14 & 0,8 & 318 & 4 & 0,2 \\
\hline 121 & 26 & 1,4 & 321 & 2 & 0,1 \\
\hline 123 & 16 & 0,9 & 323 & 2 & 0,1 \\
\hline 211 & 108 & 6,0 & 1110 & 111 & 6,2 \\
\hline 212 & 1 & 0,1 & 1111 & 38 & 2,1 \\
\hline 213 & 17 & 1,0 & 1210 & 3 & 0,2 \\
\hline 214 & 4 & 0,2 & Total & 1790 & $100 \%$ \\
\hline
\end{tabular}

Table 8

Evaluation of the potential application of prefabricated linear panels [30].

\begin{tabular}{|c|c|c|}
\hline Final Code & Prefabricated panel typology & $\begin{array}{c}\text { Evaluation of the potential } \\
\text { number of panels }\end{array}$ \\
\hline $\begin{array}{c}\text { Code } 111 \\
\text { Code } 113 \\
\text { Code } 1110 \\
\mathbf{4 3 , 1 \%}\end{array} \quad$ & \\
\hline
\end{tabular}


Table 9

Evaluation of the potential application of prefabricated nonlinear panels [30]

\begin{tabular}{|c|c|c|}
\hline Final Code & Prefabricated Panel typology & $\begin{array}{c}\text { Evaluation of the potential } \\
\text { number of panels }\end{array}$ \\
\hline$\sum \quad$ Code 118 & & \\
\hline
\end{tabular}

Table 10

Evaluation of the potential application of prefabricated modules which allow the creation indoor spaces [30]

\begin{tabular}{|c|c|c|}
\hline Final Code & Prefabricated Panel typology & $\begin{array}{c}\text { Evaluation of the potential number } \\
\text { of panels }\end{array}$ \\
\hline $\begin{array}{l}\text { Code } 211 \\
\text { Code } 217 \\
\text { Code } 311 \\
\text { Code } 313 \\
\text { Code } 317 \\
\mathbf{3 9 , 4 \%}\end{array}$ &
\end{tabular}

\section{Conclusions}

After the development of this study it is now possible to know some conclusions about the same. A significant part of the Portuguese housing stock is outdated, the implementation of the new European Directive 2010/31/EU emerges as an opportunity to rehabilitate the building stock, turning it more efficient and sustainable. Moreover the majority of the Portuguese building stock was built in a time with inexistent thermal regulation these buildings tend to consume more energy than necessary. The thermal inefficiency of the construction in the Portuguese Building Stock has negative consequences, not only for the dwellers but also for the country economy. This can be a unique opportunity to correct the past mistakes. The rehabilitation appears as an opportunity to upgrade the existing building stock, increasing their energy efficiency, comfort conditions and market value. 
At the moment there are several techniques of energy retrofitting buildings facades. The international project IEA ECBCS Annex 50 proposes an innovative technique of retrofitting through the use of prefabricated panels. Nevertheless due to the specificities of the prefabrication industry but also to the specificities of the rehabilitation market it was necessary to do an approach of the building stock in order to evaluate if there were a significant potential number of buildings capable of being retrofit using this technique.

Through the statistical data it was possible to determine that, in 2011, existed 3.544.389 buildings in Portugal but not all had the conditions to be part of the present study. In order to know those buildings with better conditions to be retrofitted using this technique three variable were established, namely:

- The number of floors - only buildings with more than one and less than seven floors were considered;

- The period of construction - All the buildings built before 1990 were considered;

- With reparations needs in the exterior walls and window frames.

It was possible to conclude that in the analyzed period existed 772.485 buildings that could be a potential target of an energy retrofit using the prefabricated panels.

The choice of a prefabricated panel is connected with the morphology of the façade and the openings type that exist in the same. There is no statistical information about such theme reason why a study of the buildings morphology was done in loco. In order to have a significant sample 132 buildings which attended to the three variables requested were observed in an extensive geographical area. During this observation in loco the buildings opening were classified. This observation was done in two different stages, the first observation was held in Porto, Póvoa de Varzim and Vila do Conde. In total were accounted 1282 openings in 93 buildings.

In the second sample were accounted 508 openings in 39 buildings placed in Espinho, Vila Nova de Gaia, Valongo, Maia, Matosinhos and Santa Maria da Feira. In the end it was possible to know that the most frequent opening in the first sample corresponded to the codes $111,113,114,118,211,217,311,313,317,1110$ and in the second sample to the codes $111,113,118,211,311,313,317$ and 1110 . It was possible to establish a correspondence between the most relevant codes of the first and second sample.

With the potential number of buildings able to be retrofitted using the prefabricated technique and the total percentage of the most representative codes of the 132 buildings observed in loco it was possible to estimate the number of openings suitable for a different type of prefabricated panel.

It is possible to conclude that there are three types of prefabricated panels with major application, prefabricated linear panels, prefabricated nonlinear panels and prefabricated modules which allow the creation indoor spaces.

It was estimated a total potential application of 8.987 .864 prefabricated panels, namely, 4.514 .883 prefabricated linear panels, 345.687 prefabricated nonlinear panels and 4.127.294 prefabricated modules which allow the creation indoor spaces. The first type of panels is those which major potential of application. Is it possible to conclude that exists potential for the energy retrofit of facades using the innovative technique 
of the project IEA ECBCS Annex 50 though initially seems a bold solution compared to traditional techniques is a solution that arguably presents technical and economical advantages due to prefabrication and which allows to have in consideration the life cycle of the buildings.

\section{REFERENCES}

1. Regulamento das Características de Comportamento Térmico dos Edifícios (RCCTE), (Thermal Buildings Regulation, in Portuguese). Decree-Law n. ${ }^{\circ} 40 / 90$, of February $6^{\text {th }}, 1990$.

2. M.S. Todorovic, J.T. Kim, Buildings energy sustainability and health research via interdisciplinarity and harmony, Energy and Building 47 12-19, 2012.

3. F. Umbach. Global energy security and the implications for the EU. Energy Policy, 38, pp. 1229-1240, 2010.

4. J. Bielecki. Energy security: Is the wolf at the door? The Quarterly Review of Economics and Finance, 42, pp. 235-250, 2002.

5. UNFCCC, 2010. Kyoto Protocol. United Nations Framework Convention on Climate Change. http:// unfccc.int/kyoto_protocol/items/2830.php

6. Panorama of Energy. Statistical Office of the European Communities. Eurostat, 2009.

7. Energy, transport and environment indicators. Statistical Office of the European Communities. Eurostat, 2009.

8. Sousa, J.; Silva, S.; Almeida M., 2012, "Enquadramento Energético do Sector Residencial Português" (Energetic Background of Portuguese Residencial Sector) presented to "Seminário Reabilitação Energética de Edifícios" (Building Energetic Retrofit Seminar) organized by Civil Engineering Department (DEC). University of Minho, held 28th September 2012, Guimarães, 2012.

9. Presidência do Conselho de Ministros. Resolução do Conselho de Ministros N. ${ }^{\circ}$ 29/2010, Diário da República 1.a série N. ${ }^{\circ}$ 73. Lisbon, 2010.

10. European Directive 2002/91/CE of the European Parliament and the Council of 16 December 2002 on the energy performance of buildings. Official Journal of the European Communities $n .{ }^{\circ} \mathrm{L} 1$ of January 4, 2003, pp. 65-71. European Union, Brussels, 2002.

11. B. Poel, G. van Cruchten, C.A. Balaras, Energy performance assessment of existing dwellings, Energy and Building 39 pp.393-403, 2007.

12. European Directive 2010/31/EU of the European Parliament and the Council of 19 May 2010 on the energy performance of buildings (recast). Official Journal of the European Communities n. ${ }^{\circ}$ L 153, of June 18, 2010. pp. 1-26. European Union, Brussels, 2010.

13. Zimmermann, Mark. Status Report 1ECBCS ExCo meeting, Oslo, Norway, June 15-16, 2006. EMPA, Duebendorf, 2006.

14. P. Silva, M. Almeida, L. Bragança, V. Mesquita. Performance evaluation of non-conventional constructions: Case study in a temperate climate. Applied Thermal Engineering 42 pp.136-144, 2012.

15. G. Habert, E. Castillo, E. Vincens, J.C. Morel. Power: A new paradigm for energy use in sustainable construction. Ecological Indicators 23 pp.109-11, 2012.

16. J. A. Reis, P. Escórcio. Energy certification in St. António (Funchal) - Statistical analysis. Energy and Buildings 49 pp.126-131, 2012.

17. C. Petersdorff, et al., Mitigation of $\mathrm{CO} 2$ emissions from building stock, in: Beyond the EU Directive on the Energy Performance of Buildings, Ecofys, Cologne, Germany, 2004.

18. H. Tommerup, S. Svendsen. Energy savings in Danish residential building stock. Energy and Buildings 38 pp. 618-626, 2006. 
19. Annex 50 Prefabricated Systems for Low Energy Renovation of Residential Buildings. http://www. ecbcs.org/annexes/annex50.htm, website consulted on $28^{\text {th }}$ December 2012.

20. Corvacho, H., Sousa, J., Pereira, L. P. and Quintela, M. (2011), Low Energy Renovation of Buildings Using Prefabricated Systems, 12th International Conference on Durability of Building Materials and Components, Faculty of Engineering, University of Porto, Porto, Portugal, April 12th-15 ${ }^{\text {th }}, 2011$.

21. Schwehr, P., Fischer, R., Geier, S. \& Höfler, K. 2010 (draft) 'Retrofit Strategies Design Guide. Advanced Retrofit Strategies \& 10 Steps to a Prefab Module', IEA ECBCS Annex 50, Prefabricated Systems for the Low Energy Renovation of Residential Buildings, 112 pp., Swiss Federal Laboratories for Materials Testing and Research, Switzerland, 2010.

22. Geier, S., Höfler, K., Cousin, S., Silva, P., Kobler, R., 2010 (draft) 'Retrofit Module Design Guide', IEA ECBCS Annex 50, Prefabricated Systems for the Low Energy Renovation of Residential Buildings, 133 pp., Swiss Federal Laboratories for Materials Testing and Research, Switzerland, 2010.

23. D. Brounen, N. Kok, J. M. Quigley. Residential energy use and conservation: Economics and demographics. European Economic Review. July 2011.

24. Ayers, Ian, Sophie Raseman, Alice Shih. Evidence from two large field experiments that peer comparison feedback can reduce residential energy usage. NBER Working Paper 15386, 2009.

25. Census 2011.http://www.ine.pt/scripts/flex_definitivos/anim_censos2011.html, website consulted on 28th December 2012. Lisbon, 2012.

26. Abreu, I.; Corvacho, H., 'Os Novos Desafios Tecnológicos na Reabilitação Energética de Paredes Exteriores de Edifícios' (The New Technological Challenges in the Low Energy Retrofit of External Walls of Buildings), in Construção Magazine, $\mathrm{n}^{\circ}$ 35, Publindústria, pp 23-28. Porto, 2010.

27. Sousa, J.; Almeida M.; Silva, S.; Bragança L.; Silva P., 2013, 'Análise da Evolução da Transmissão Térmica das Paredes de Fachada em Portugal' (Analysis of the Evolution of Thermal Tranfer of Facade Walls in Portugal), in Construção Magazine, $\mathrm{n}^{\circ}$ 58, Publindústria. Porto, 2010.

28. Inquérito ao Consumo de Energia no sector doméstico 2010. (Survey on Energy Consumption, in Portuguese). National Institute of Statistics and General Directorate for Energy and Geology, Lisbon, 2011.

29. Sousa, J. 2010, 'Potencial de Aplicação de Sistemas Pré-fabricados na Reabilitação Térmica de Fachadas' (Potential Application of Prefabricated Systems for the Retrofit of Facades), Ms. Sc. Thesis, 118 pp, Faculty of Engineering of the University of Porto, Portugal. Porto, 2010.

30. Schwehr, Peter; Fischer, Robert. Building Typology and Morphology of Swiss Multi-Family Homes 1919-1990. Lucerne University of Applied Sciences and Arts (HSLU), Lucerne School of Engineering and Architecture (HSLU), Competence Centre for Typology and foresight Planning in Architecture (CCTP), Switzerland, January 2010. 